\title{
Remote Sensing of Fruit Textural Changes with a Laser Doppler Vibrometer
}

\author{
Noboru Muramatsu \\ Department of Breeding, National Institute of Fruit Tree Science, Ministry of Agriculture Forestry and \\ Fisheries, Tsukuba, Ibaraki 305-8605, Japan \\ Naoki Sakurai \\ Environmental Studies, Faculty of Integrated Arts and Sciences, Hiroshima University, Kagamiyama, \\ Higashi-Hiroshima 739-0046, Japan \\ Naoki Wada \\ Research and Development Laboratory, Mastushita-Kotobuki Electric Industries Ltd., Saijo, Ehime 793- \\ 0035, Japan
}

\author{
Ryoichi Yamamoto \\ Laboratory of Biology, Tezukayama College, Nara 631-0034, Japan
}

Keiichi Tanaka, Toshikazu Asakura, and Yuko Ishikawa-Takano

Department of Breeding, National Institute of Fruit Tree Science, Ministry of Agriculture Forestry and Fisheries, Tsukuba, Ibaraki 305-8605, Japan

Donald J. Nevins
Department of Vegetable Crops, University of California, Davis, CA 95616

AdDitional INDEX words. Malus $\times$ domestica, Actinidia deliciosa, Diospyros kaki, ethylene, texture, fruit quality, viscoelastic property

\begin{abstract}
Developmental changes in fruit texture during ripening were determined based on remote sensing of surface vibrations. The technique was evaluated with fruit having a range of firmness and textural characteristics including kiwifruit [Actinidia deliciosa (A. Chev.) Liang et Ferguson, 'Hayward'] treated with ethylene, apple (Malus $\times$ domestica Borkh. 'Ourei') stored at 10 or $20^{\circ} \mathrm{C}$ and persimmon (Diospyros kaki $\mathrm{L}$. 'Fuyu') stored at $10{ }^{\circ} \mathrm{C}$. In each case fruit were placed on a stage capable of imparting sine wave vibrations with frequencies ranging from 5 to $2,000 \mathrm{~Hz}$. The vibration transmitted through the fruit to the top surface was precisely measured without any direct contact with the Doppler laser vibrometer. The perceived fruit surface signal was corrected by subtraction of the stage vibration based on an accelerometer signal, hence the true vibrational signal of the fruit mass was determined. The phase shift at selected frequencies was based on the difference between the input and output vibration. The phase shift significantly increased in the range of 1,200 to $1,600 \mathrm{~Hz}$ in all three kinds of fruit analyzed as a function of maturation. The resonance frequency, peak height, and peak width of second resonance peak were also determined. The resonance frequency decreased in all fruit as a function of maturation. In apple, the peak height decreased as a function of storage duration, but in kiwifruit and persimmon the peak height fluctuated and a consistent pattern in this particular parameter was not observed. The amplitude of vibration decreased as a function of maturation when the imposed vibration exceeded 1,200 Hz. Data clearly showed that the Doppler laser vibrometer is capable of detecting the phase shift and vibration amplitude of fruit, and can be used as a versatile remote sensory tool for determining fruit firmness and for evaluations of maturity.
\end{abstract}

A primary objective of studies on postharvest handling has always been to sustain the efficient delivery of safe, high quality fresh agricultural products to consumers. One means of achieving this objective is to precisely monitor changes in physical status using several external parameters. In most sorting lines size, shape, color, and absence of exterior blemishes comprise the major criteria for screening. However, just as important in the assessment of quality are concealed properties such as sugar content, soluble solids and acidity but these components do not necessarily correlate with external appearance and assessment requires additional sampling and analysis. One other determinant of quality is internal fruit

Received for publication 10 Sept. 1998. Accepted for publication 9 June 1999. We thank the staff of the Persimmon and Grape Research Center, National Institute of Fruit Tree Science, Ishikawa Prefecture Agricultural University and Kyoto University for supplying fruit. The cost of publishing this paper was defrayed in part by the payment of page charges. Under postal regulations, this paper therefore must be hereby marked advertisement solely to indicate this fact.

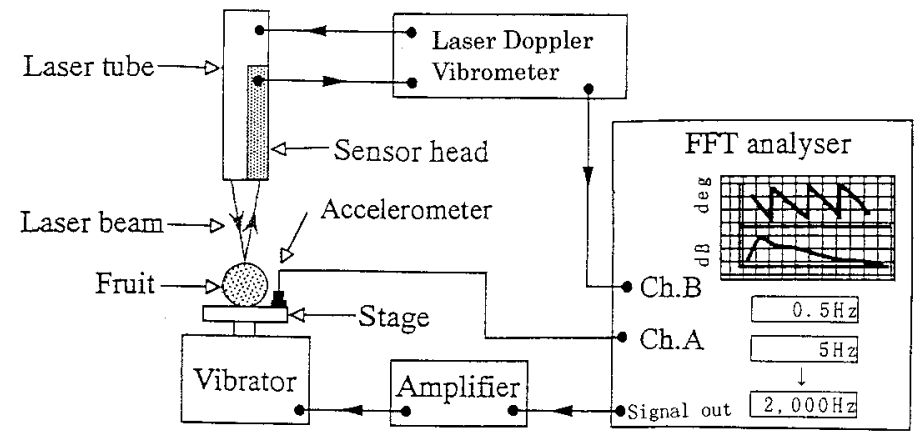

Fig. 1. A schematic diagram illustrating the remote measurement of fruit quality with a laser Doppler vibrometer. The Fast Fourier Transformation (FFT) Analyzer was used to generate the frequency signal over a range of from 5 to $2,000 \mathrm{~Hz}$ at $0.5 \mathrm{~Hz}$ increments. The intensity of signal was amplified to control the intensity of the vibration at the stage. The fruit sample was placed in contact with the stage through a small amount of clay. A laser beam emitted by the source is reflected from the surface of fruit to back to the sensor head. The reference signal at the vibration stage measured by the accelerometer was subtracted from the LDV signal. 


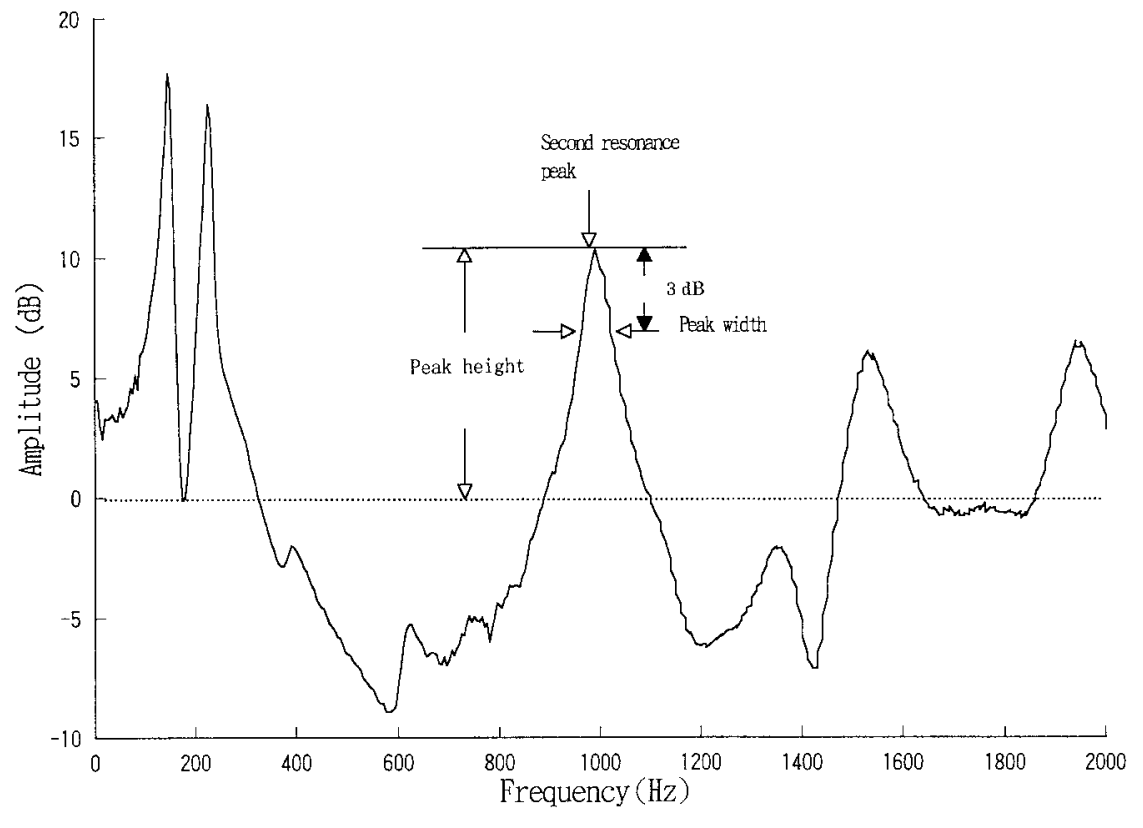

Fig. 2. A representative example of resonance in the vibrational amplitude of apple as a function of imposed frequency. Three parameters-second resonance frequency, peak height, and peak width-were determined from the resonance peak. The peak width was measured at $3 \mathrm{~dB}$ below the peak maximum.

texture. Texture is even more difficult to define objectively but it is an increasingly important value in quality assessment. Traditional methods for texture evaluation generally require destructive sampling of individual fruit which limit the estimation of maturity variation in bulk shipments after harvest or during storage. Therefore a more comprehensive, nondestructive, remote method for product texture evaluation would have distinct advantages for quality control.

Shmulevich et al. (1996) compiled a list of the promising methods for nondestructive fruit texture analysis: 1) fruit responses to imposed vibrations (Abbott et al., 1992; Finney, 1967), 2) the response of fruit to mechanical or sonic impulse (Yamamoto and Haginuma, 1984a, 1984b, 1984c), 3) impact force analysis (Armstrong et al., 1990; Chen et al., 1993), and 4) ultrasonic testing techniques (Galili et al., 1993; Mizrach et al., 1989; Zebrowski, 1992).

Since plant tissues are characterized as viscoelastic substances, identification of the contribution of viscosity and elasticity should provide pertinent rheological information about the tissue. However, in most methods mentioned above, any index that might relate to the elasticity has been derived based on calculations, and in some cases the elastic modulus was simply estimated (Cooke and Rand, 1973; Zebrowski, 1992). Several intrusive methods for strain determination have been developed to measure the viscoelastic property of plant tissue. Yamamoto et al. (1970) used the stress relaxation method with oat (Avena sativa L.) and pea (Pisum sativum L.) stems from seedling treated with or without IAA. Stress relaxation behavior was analyzed using Maxwell's viscoelastic model, with stress of the specimen determined as a function of time at constant 1997). Larsen, 1978). strain. In an adaptation of this method, Kojima et al. measured the texture changes in tomato ( $L y$ copersicon esculentum Mill.) (1991) and banana (Musa $\times$ paradisiaca L.) (1992) during ripening. Several reports describe measurement of viscoelastic property by vibrational methods. Finney (1967), Finney and Norris (1968), and Yamamoto and Haginuma (1984b) report calculations of the internal friction based on the bandwidth of the acquired resonance peak, using excised cylindrical specimens. Signal attenuation has also been used as an index for viscosity in other agricultural products. In one example, Rowan et al. (1958) measured the attenuation ratio of eggs to assess quality.

For reliable evaluation, specimens must be allowed to vibrate freely and the absolute vibrational amplitude must be determined accurately. However whenever intact fruit are subjected to vibration measurements by direct contact, any minor displacement by the sensor causes a substantial change in the measured amplitude (Muramatsu et al., 1996). We showed that if the weight of the sensor exceeded $1 \mathrm{~g}$, fruit vibration would be restricted and would affect the resonance determination (Muramatsu et al.,

A Doppler laser vibrometer (LDV) is capable of measuring surface behavior of objects at a distance. When a laser beam is reflected from the sample surface, the characteristics of the reflected beam are altered as a function of the vibrational velocity of the target object, hence with this method the vibration of an object can be monitored without direct contact. Because direct contact with the object is avoided the measurement with LDV meets the criteria for remote sensing. The method has been invaluable in vibrational studies of a number of biological materials, namely tree leaves (Martens, 1990) and insect tympanic membrane (Michelsen and

We used this LDV technique to remotely determine ripening-

Fig. 3. Phase shift in kiwifruit after ethylene treatment. A representative example of the phase shift of kiwifruit is shown at intervals after ethylene treatment. The FFT was used to determine the phase shift as a function of vibrational frequency. The frequency range was from 5 to $2,000 \mathrm{~Hz}$.

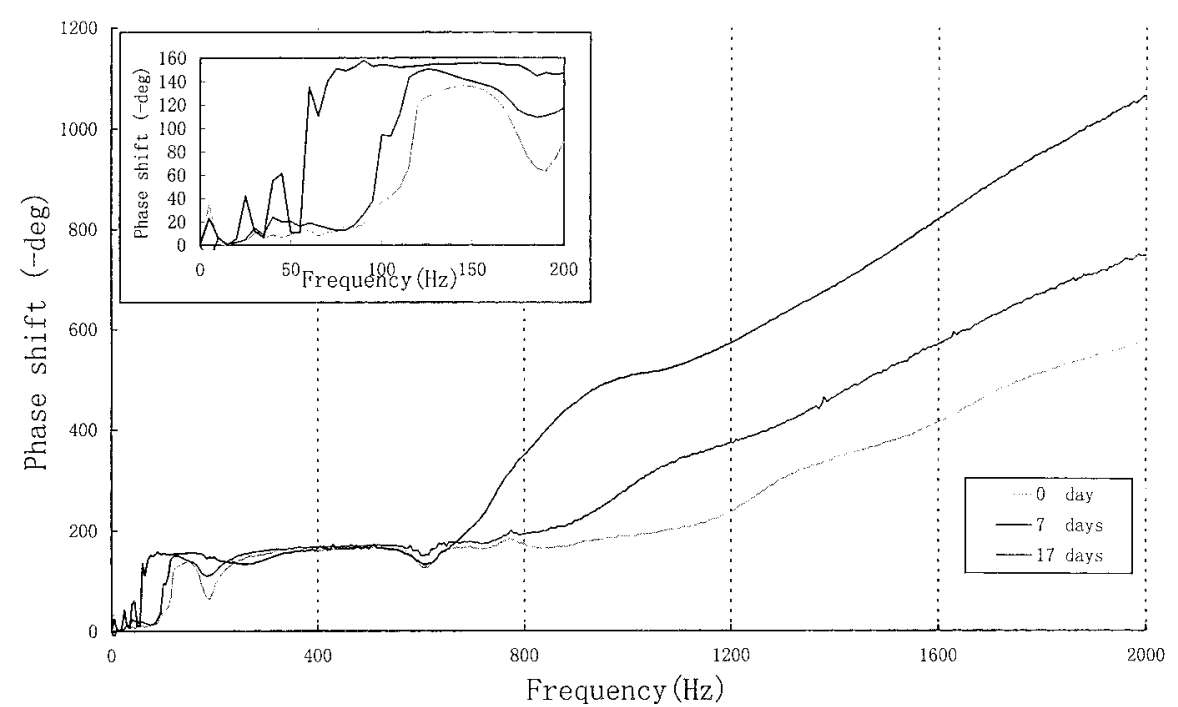




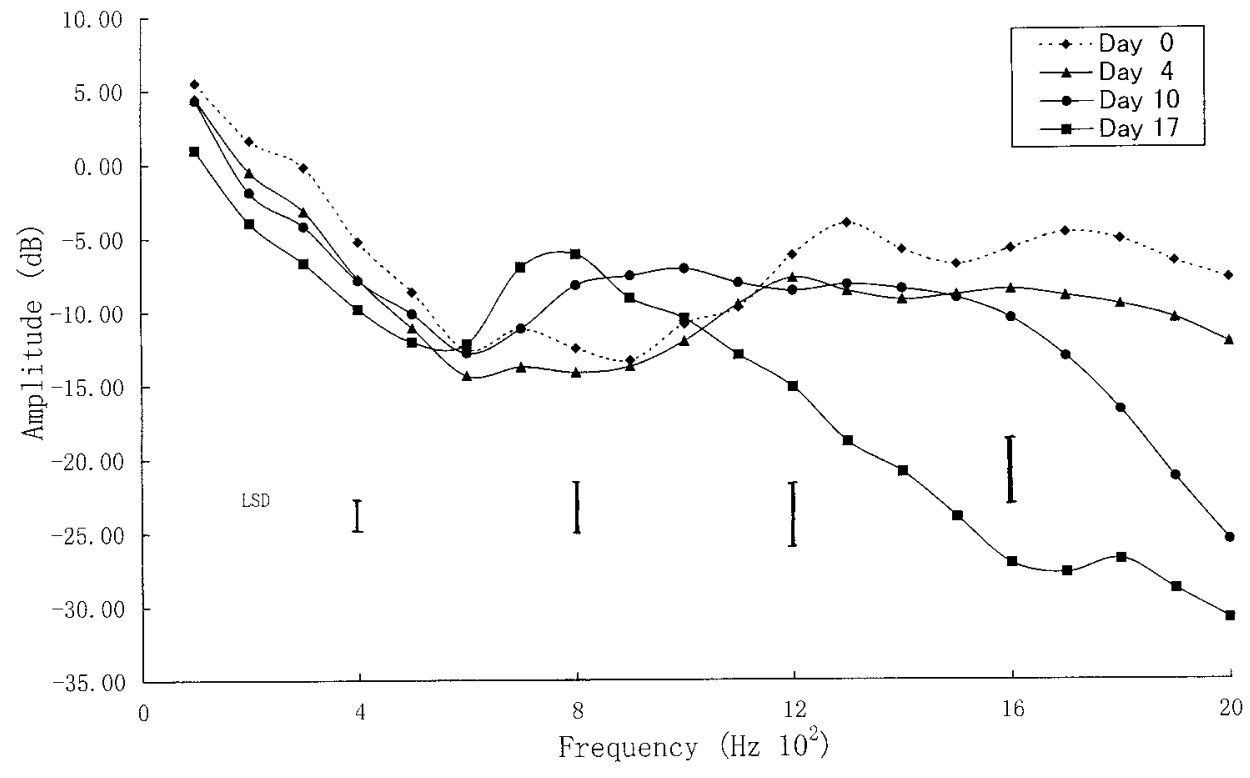

Fig. 4. Changes in the tissue vibration amplitude of kiwifruit after ethylene treatment. The relation-ships between imposed frequency and vibration amplitude were taken from the display of the FFT monitor. Kiwifruit were exposed to ethylene over a period of $17 \mathrm{~d}$. Vertical bars represent selected LSD (0.05).

dependent changes in fruit texture and the development of physiological disorders affecting internal quality based on changes in surface vibrations of intact kiwifruit (Actinidia deliciosa 'Hayward'), peach (Prunus persica Batsch. 'Akatsuki'), Japanese pear (Pyrus pyrifolia Nakai 'Cyouju'), and citrus fruit (Citrus tamurana Hort. ex Tanaka) (Muramatsu et al., 1999). As emphasized above, the measurement of the absolute amplitude of vibration is mandatory for accurate determination of viscoelastic properties. However, in our earlier report (Mura-matsu et al., 1999) we expressed the concern that the absolute vibrational attenuation could not be monitored since the amplitude at the vibration stage changed as a function of the imposed frequency. This study is an evaluation of a technique to improve the determination of the parameters involved in the second resonance peak and refinements in signal acquisition to improve the reliability for measuring the textural changes during fruit ripening.

\section{Materials and Methods}

Plant materials. 'Hayward' kiwifruit were provided by the Grape and Persimmon Research Center, National Institute of Fruit Tree Science, Hiroshima. Fruit were treated with $400 \mu \mathrm{L} \cdot \mathrm{L}^{-1}$ ethylene to induce ripening. The fruit were stored at $20^{\circ} \mathrm{C}$ until LDV and firmness measurements which were taken at 2 or 3 dintervals. Three to five fruit were subjected to determination for each analysis.

'Ourei' apples were provided by Ishikawa Prefecture Agricultural College. Some of the fruit were stored at $20^{\circ} \mathrm{C}$ for 2 weeks and others $10^{\circ} \mathrm{C}$ for 8 weeks. The samples were placed in polyethylene bags to suppress desiccation. The samples were taken at an interval of 2 or 3 weeks for LDV and texture measurement. Three or four fruit were subjected for texture analysis at each analysis.

'Fuyu' persimmon fruit were provided by Kyoto University. The samples were placed in polyethylene bag, and stored at $10^{\circ} \mathrm{C}$. Three or four samples were taken every week for LDV and texture measurements.

DOPPLER LASER MEASUREMENTS. Fruit vibration in response to specific frequencies was determined using a Doppler laser vibrometer (LDV). Figure 1 is a schematic diagram of the components used for remote LDV measurements. A single fruit was placed on a vibration stage (model 512A; EMIC Co. Ltd., Tokyo, Japan). To ensure the effective transmission of the vibration, a small amount of soft clay was placed directly between the vibrator stage and the sample. A Fast Fourier Transformation (FFT) Analyzer (CF360; ONO SOKKI Co. Ltd., Yokohama, Japan) was used to generate discrete sine waves over a range of 5 to $2,000 \mathrm{~Hz}$ at 0.5 $\mathrm{Hz}$ increments. The signal was increased with a power amplifier (model 371-A, EMIC Co. Ltd.) to enhance its strength. An accelerometer (NP-3110; ONO SOKKI Co. Ltd., weight $=5.1 \mathrm{~g}$ ) was fixed on the vibration stage to monitor the reference signal. In a preliminary experiment (Muramatsu et al., 1999), the output signal of the FFT was used as reference signal, but we found that this vibration was not reliable. The transmitted vibration at the top surface of fruit was measured by a Doppler laser vibrometer (LV1300; ONO SOKKI Co. Ltd.). Since the LDV and accelerometer monitor the velocity and acceleration, respectively, the data from
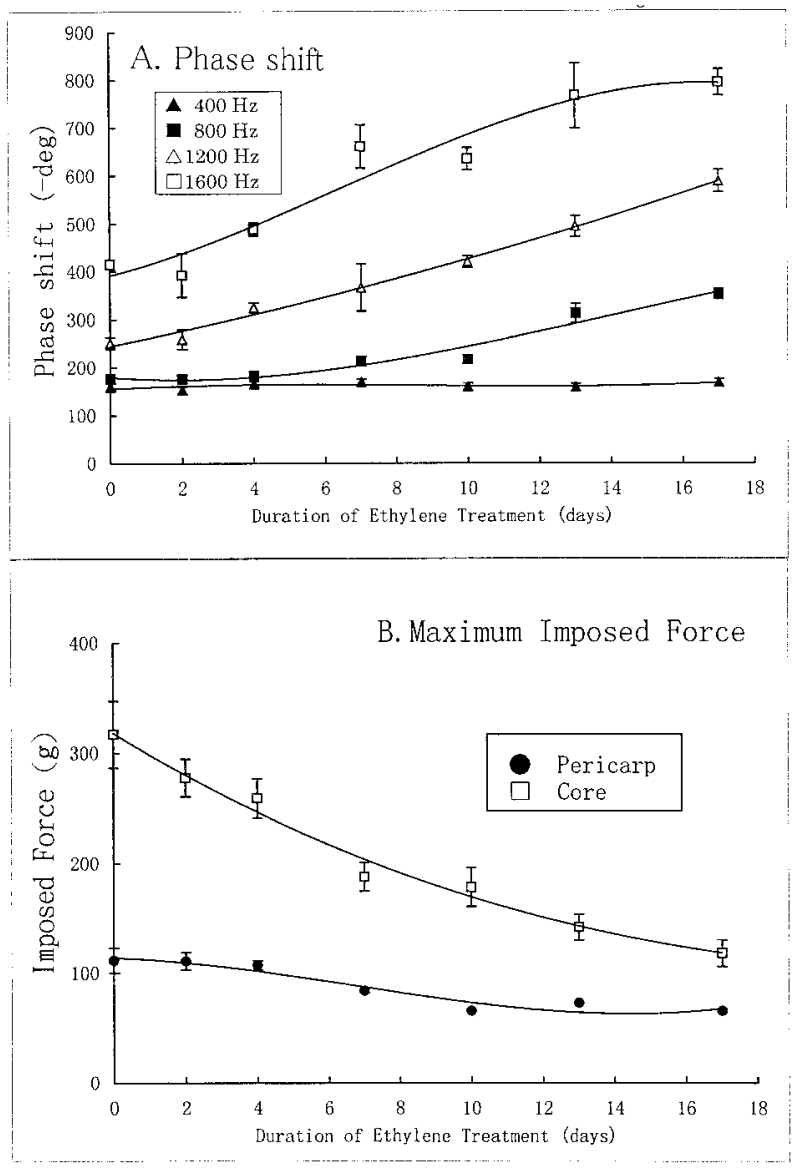

Fig. 5. Changes in parameters related to firmness during ethylene treatment in kiwifruit. (A) The phase shift, (B) the maximum force imposed by the rheometer. See the caption in Fig. 3 for details in determining the phase shift. Vertical bars indicate SE. 

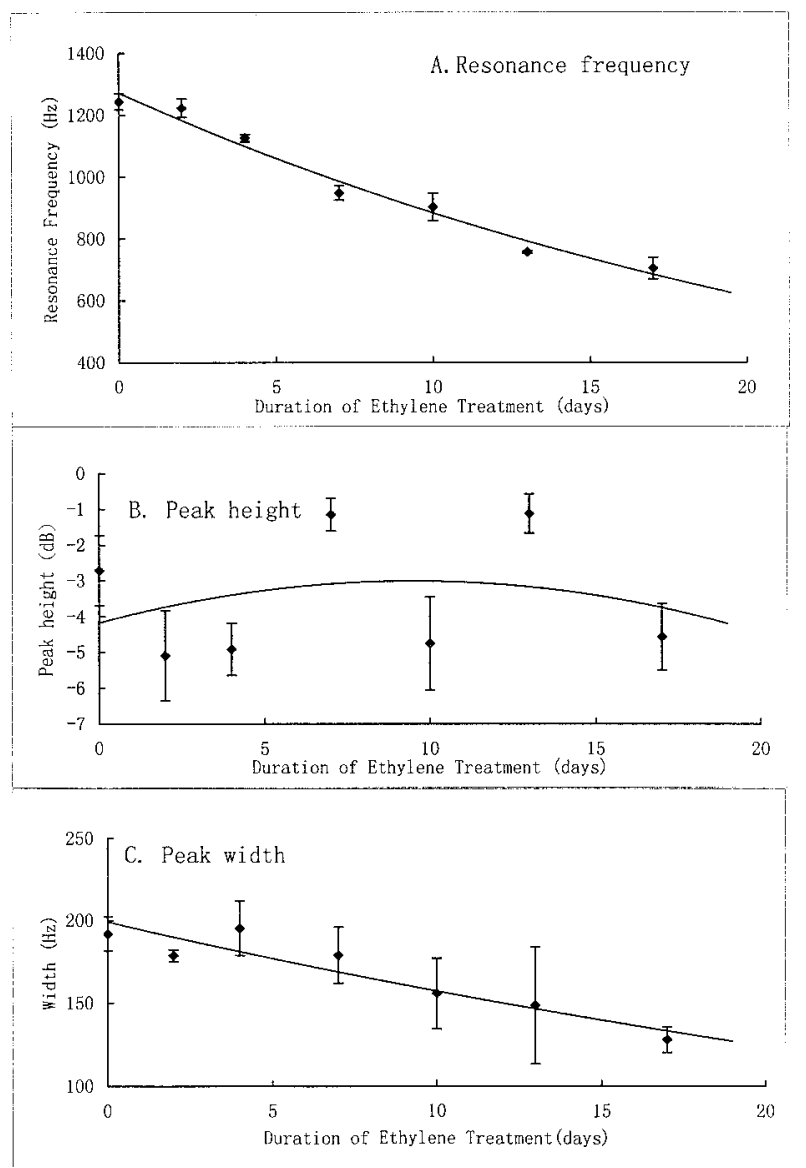

Fig. 6. Changes in several parameters related to the second resonance phenomenon in kiwifruit as a function of the duration of ethylene exposure. (A) Second resonance frequency, (B) peak height, (C) peak width. See the caption in Fig. 2 for details about the determination of each of these parameters. Vertical bars indicate SE.

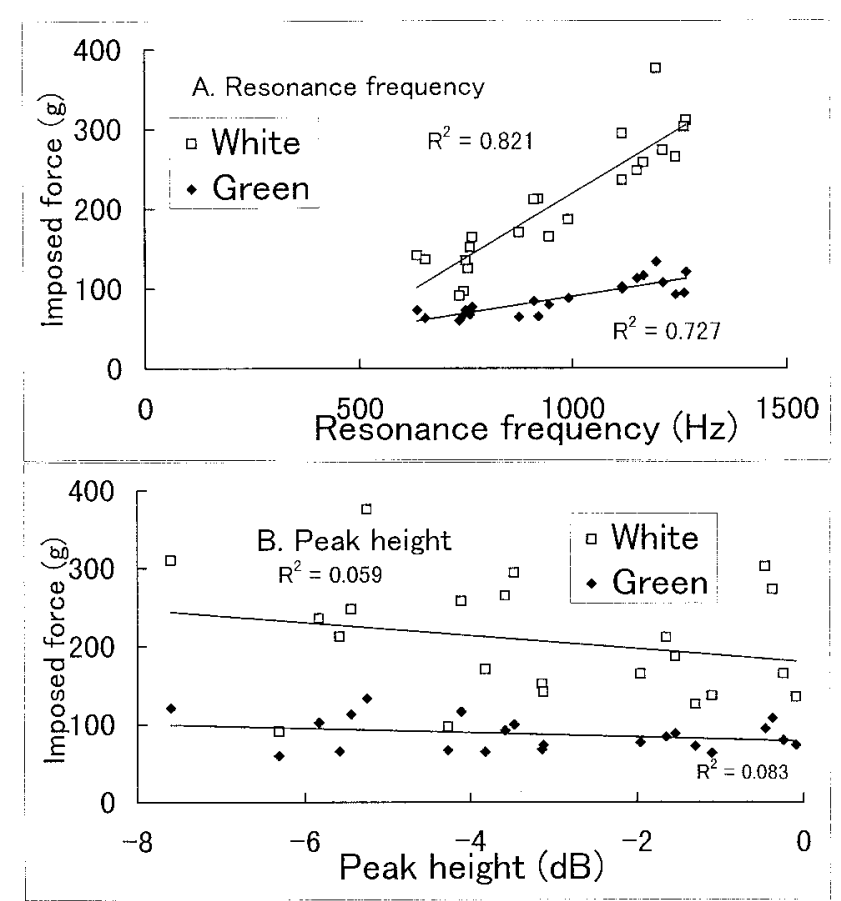

Fig. 7. Relationship between the force imposed by the rheometer and parameters of second resonance including (A) resonance frequency, (B) peak height. Green and white indicate pericarp and core of kiwifruit, respectively. the LDV were differentiated to obtain acceleration. Hence the output of both sensors were adjusted to the same physical units in order to subtract a reference signal from LDV signal. The phase shift and amplitude difference between the signal of the accelerometer and that of LDV were displayed on the screen monitor. The phase shift response was monitored at 400, 800, 1,200, and 1,600 Hz.

When the LDV was used to directly monitor the stage vibration, the vibrational amplitude and phase shift was nearly zero at all the imposed frequency, hence vibration at stage required an accelerometer for effective monitoring. The absolute attenuation of vibration transmitted through fruit surface was detectable. The frequency of the second resonance peak, height and width of the peak were determined from the amplitude of the vibration (Fig. 2).

Direct MEASUREMENT OF FRUIT TEXTURE. After being subjected to LDV analysis, the firmness of the same fruit was directly measured on transverse slices $(1 \mathrm{~cm}$ thick). The slices were placed on the stage of the rheometer(RT-2002; D.D. Fudo Co. Ltd., Tokyo, Japan). Firmness was determined $1 \mathrm{~cm}$ from the edge of fruit at triplicate sampling sites on each fruit. A cylindrical probe $(3 \mathrm{~mm}$ in diameter) with a load sensor was inserted to the slice to a depth of $0.5 \mathrm{~mm}$ at the rate of $2 \mathrm{~cm} \cdot \mathrm{min}^{-1}$. The maximum imposed force to achieve $0.5 \mathrm{~mm}$ penetration was recorded by the personal computer (PC-9801; NEC, Tokyo, Japan) interfaced with the rheometer.

Data Analysis. The data in Fig. 2 were taken with frequencies at $0.5 \mathrm{~Hz}$ increments. The resonance frequency, peak width and the peak height in the second resonance were determined from the original data as shown in Fig. 2. The average vibration amplitude
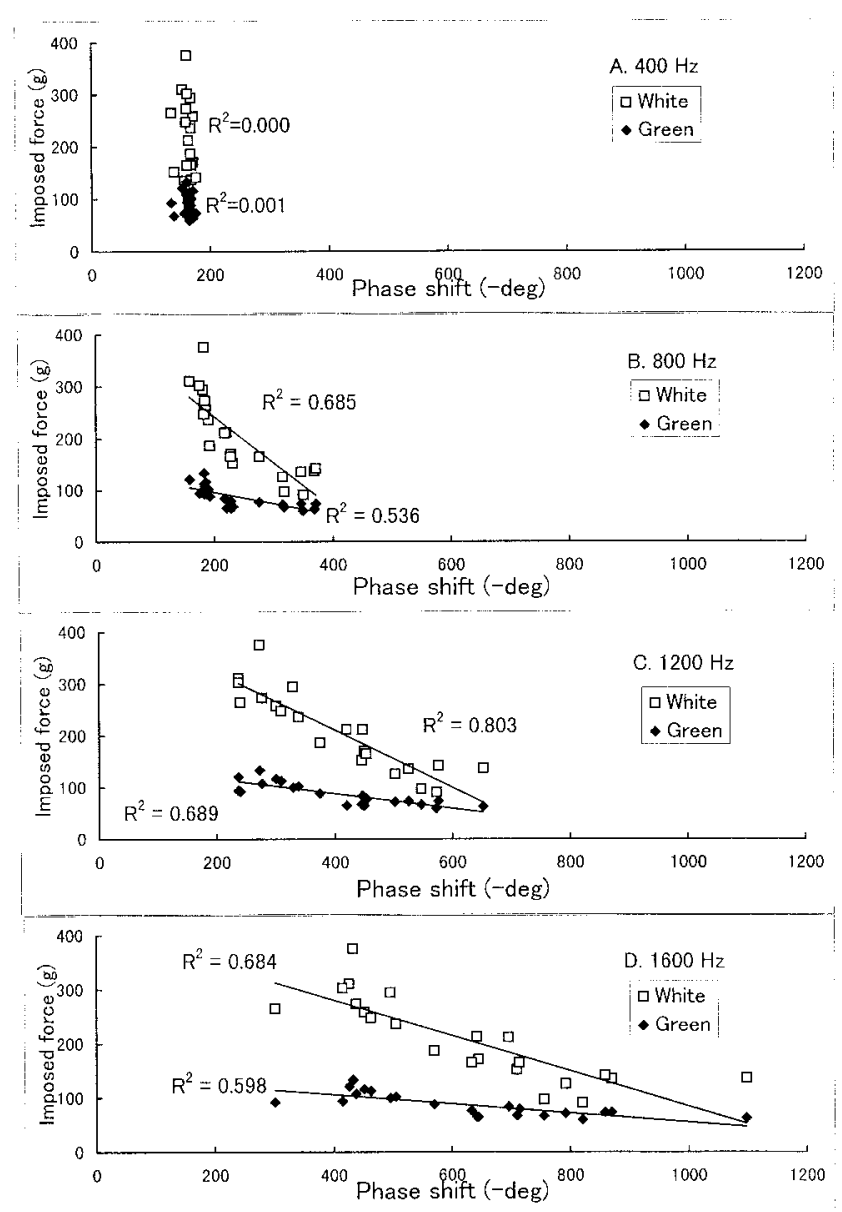

Fig. 8. Relationship between the maximum force imposed by the rheometer and the magnitude of phase shift at (A) $400 \mathrm{~Hz},(\mathbf{B}) 800 \mathrm{~Hz},(\mathbf{C}) 1200 \mathrm{~Hz}$, and (D) $1600 \mathrm{~Hz}$ in kiwifruit. 
was calculated at each 100-Hz interval, from which LSD at every 400 $\mathrm{Hz}$ was determined. Statistical procedures and curve fitting were performed using Microsoft EXCEL.

\section{Results}

In kiwifruit the phase shift between the input signal at the vibration stage and that at the top surface of the sample was clearly detected (Fig. 3). The phase shift was found to be a function of imposed frequency and the pattern of changes was related to maturity. At 0 and $7 \mathrm{~d}$ after exposure to ethylene we found similar distinct phase shifts at about $120 \mathrm{~Hz}$ but after $17 \mathrm{~d}$ the corresponding initial shift was at $60 \mathrm{~Hz}$ (Fig. 3 inset). After the initial ethyleneinduced changes, the phase shift stabilized from 300 to $600 \mathrm{~Hz}$ irrespective of the duration of ethylene exposure. At frequencies $>600 \mathrm{~Hz}$, ethylene-induced ripening in kiwifruit resulted in an enhancement of the phase shift with a clear distinction in the extent of the shift at the three sampling times.

The absolute amplitude of kiwifruit vibration ranged from 5 to $30 \mathrm{~dB}$ over the frequency range (Fig. 4). Fruit subjected to ethylene treatment did not alter the amplitude, at excitation frequencies below $600 \mathrm{~Hz}$, but significantly depressed the amplitude, when the imposed vibration frequency was $>1,200 \mathrm{~Hz}$.

The tissue exposed to ethylene treatment for as long as $17 \mathrm{~d}$ showed no distinct phase shift at $400 \mathrm{~Hz}$ (Fig. 5). However, at 1,200 and $1,600 \mathrm{~Hz}$ the ethylene treatment significantly increased the phase shift after $4 \mathrm{~d}$. The physical force required for penetration into

\section{A. $20{ }^{\circ} \mathrm{C}$ storage}

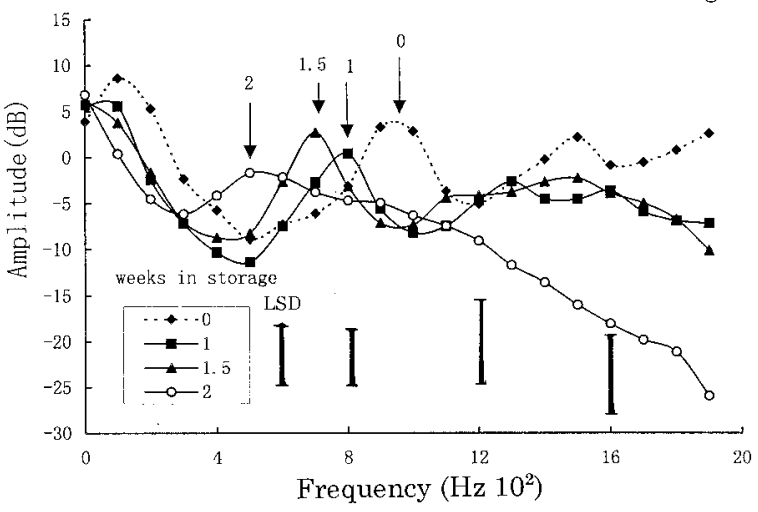

B. $10{ }^{\circ} \mathrm{C}$ storage

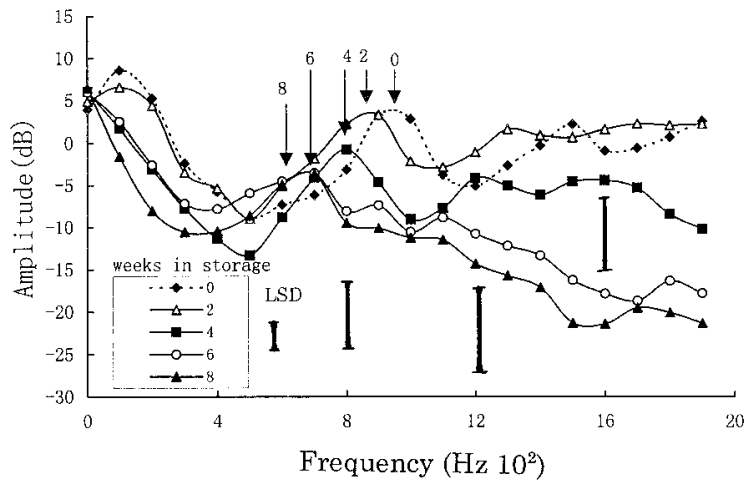

Fig. 9. Changes in amplitude as a function of frequency during apple storage at different temperature. The relationship between imposed frequency and vibrational amplitude was taken from the display of the FFT monitor. The resonance shows changes in apple held in storage at different intervals. (A) Fruit stored at $20^{\circ} \mathrm{C}$ for 2 weeks; (B) fruit stored at $10{ }^{\circ} \mathrm{C}$ for 8 weeks. Vertical bars represent selected LSD $(0.05)$. the tissue as measured by the rheometer was always higher in the white core portion than in the green pericarp. But the required force significantly decreased in both region of the kiwifruit after day 7 .

The second resonance frequency signal decreased significantly after day 4(Fig. 6). The height of the second peak was low regardless the ethylene treatment, and fluctuated between -1 and $-5 \mathrm{~dB}$. Ethylene treatment did not significantly influence the width of the second resonance peak until day 17.

The correlation coefficients between second resonance frequency and the displacement force was significant $(P<0.01)$, but we did not find significant differences between the height of resonance peak and the displacement force (Fig. 7). The correlation coefficients between the magnitude of phase shift and displacement force were significant $(P<0.01)$ at all selected frequencies except $400 \mathrm{~Hz}$ (Fig. 8).

'Ourei' apples were stored for 2 weeks at $20^{\circ} \mathrm{C}$ or for 8 weeks at $10^{\circ} \mathrm{C}$. After 8 weeks at $10^{\circ} \mathrm{C}$ apples turned mealy. The amplitude of the vibration signal ranged from between 10 to $-30 \mathrm{~dB}$ (Fig. 9). Distinct second resonance peaks between 400 and $1,100 \mathrm{~Hz}$ were visible during the first 1.5 weeks of storage at $20^{\circ} \mathrm{C}$ and for the first 4 weeks at $10^{\circ} \mathrm{C}$. When the imposed frequency was greater than $1,200 \mathrm{~Hz}$, the amplitude of the signal from fruit stored at $20^{\circ} \mathrm{C}$ for 2 weeks was significantly lower than those of other fruit. Even when the fruit were stored at $10{ }^{\circ} \mathrm{C}$, the decrease in amplitude was prominent above $1,200 \mathrm{~Hz}$ after 6 weeks of storage.

High-temperature storage of apples $\left(20^{\circ} \mathrm{C}\right)$ resulted in an increase in the phase shift at $800,1,200$, and $1,600 \mathrm{~Hz}$, but not at 400 $\mathrm{Hz}$ (Fig. 10). At $10^{\circ} \mathrm{C}$, the phase shift increased only after $35 \mathrm{~d}$ at $800,1,200,1,600 \mathrm{~Hz}$. The rate of phase shift change was higher at 20 than at $10^{\circ} \mathrm{C}$. The initial force required for penetration to a fixed
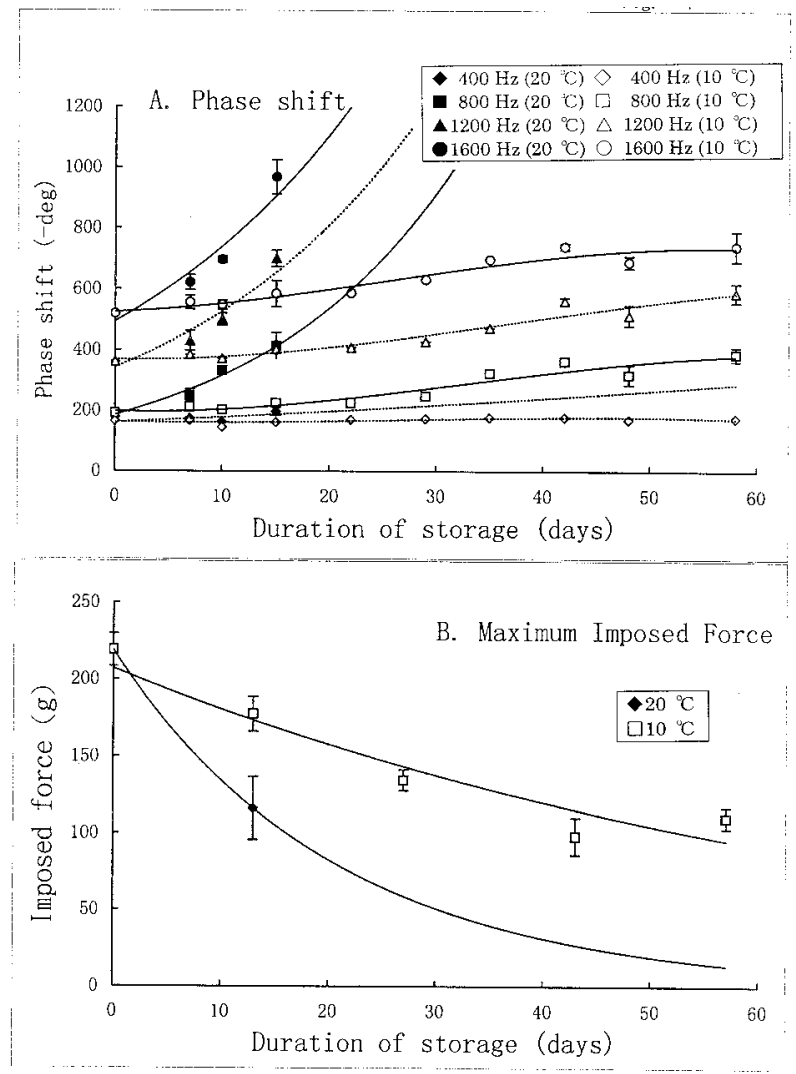

Fig. 10. Changes in phase shift and maximum force imposed by the rheometer for apple during storage. (A) Phase shift, (B) maximum force imposed by a rheometer. See Fig. 3 caption concerning phase shift. Vertical bars indicate SE. 


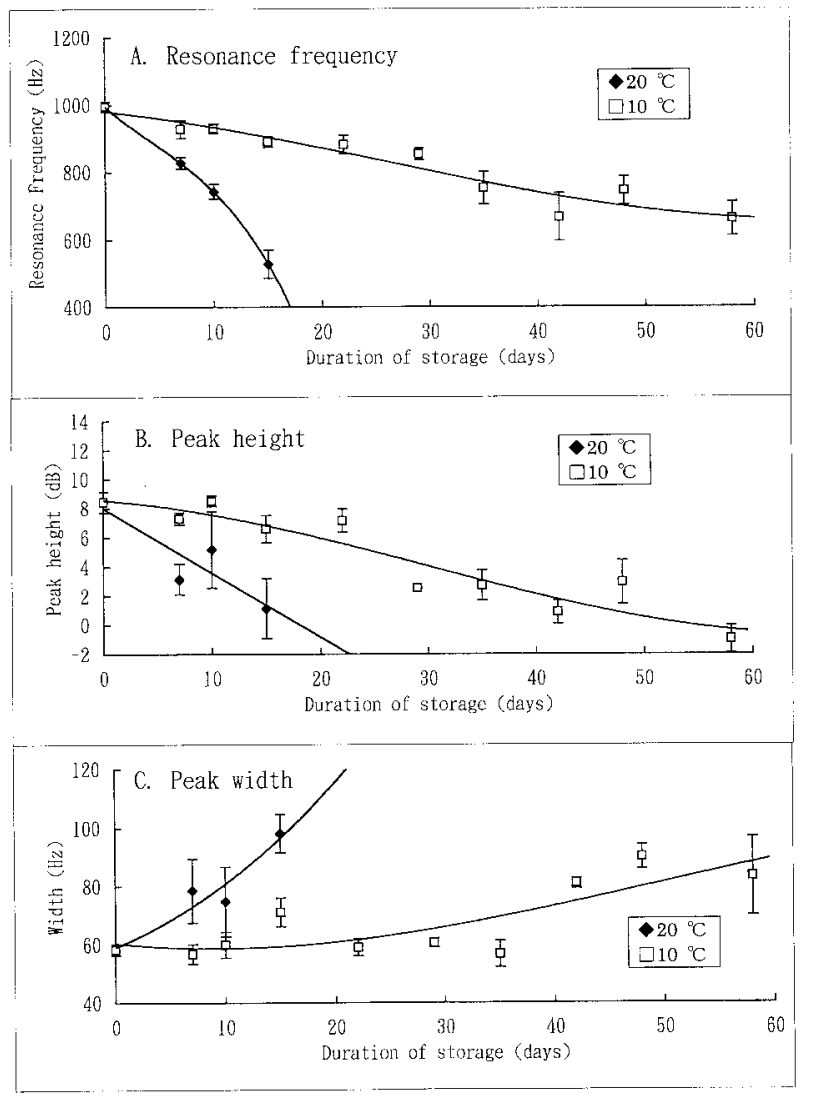

Fig. 11. Changes of parameters related to the second resonance peak during apple storage. (A) Second resonance frequency, (B) peak height, (C)peak width. See Fig. 2 caption for the determination of the values used in assessing the second resonance. Vertical bars indicate SE.
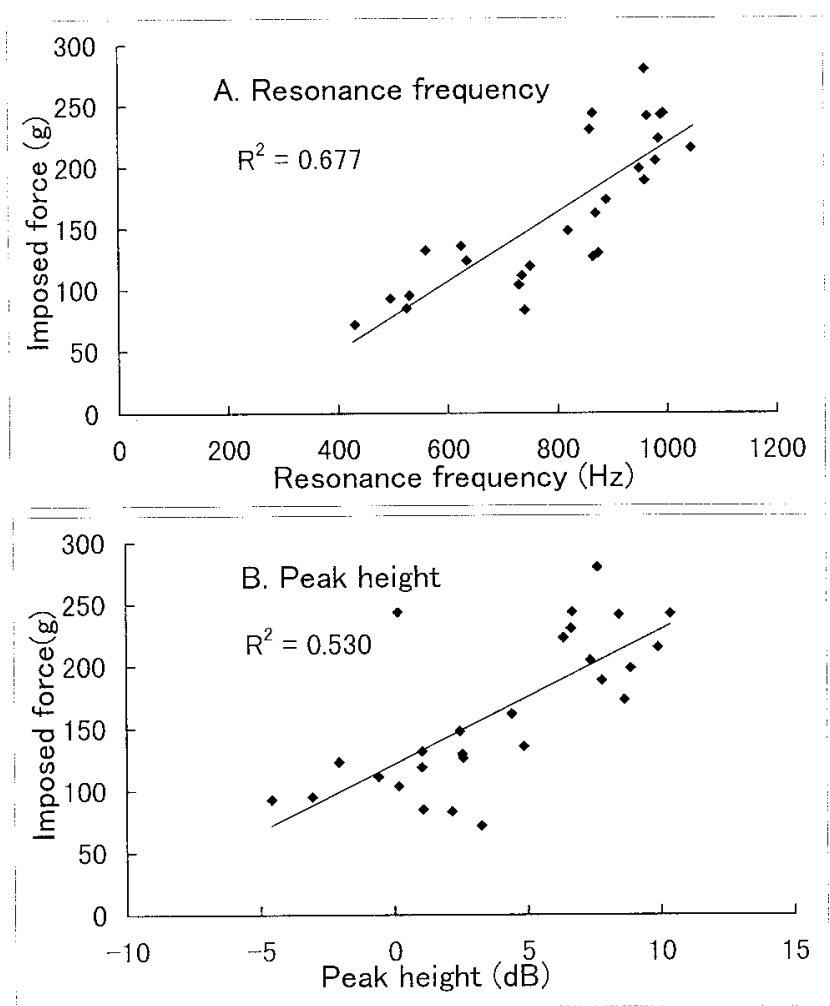

Fig. 12. Relationship between maximum force imposed by the rheometer and the parameters of second resonance for apple including $(\mathbf{A})$ resonance force, $(\mathbf{B})$ peak height. distance determined by rheological measurements decreased significantly by day 14 at $20{ }^{\circ} \mathrm{C}$. The maximum imposed force determined for apples stored at $10^{\circ} \mathrm{C}$ gradually decreased until day 42.

The second resonance frequency decreased significantly by storage at $20^{\circ} \mathrm{C}$ for $7 \mathrm{~d}$ and after $35 \mathrm{~d}$ at $10^{\circ} \mathrm{C}$ (Fig. 11). Under these condition there was a corresponding decrease in peak height and an increase in peak width. These changes, however, were not as prominent as the changes in resonance frequency, because of the large SE. Note that the peak height of apple was higher than that of kiwifruit.

The correlation coefficients between the mechanical displacement force and parameters of second resonance including the resonance frequency and peak height were significant $(P<0.01)$ (Fig. 12). The correlation coefficients between the magnitude of phase shift and displacement force were also significant $(P<0.01)$ at all selected frequencies except $400 \mathrm{~Hz}$ (Fig. 13).

With persimmon, the absolute amplitude of vibration ranged from 5 to $-25 \mathrm{~dB}$ (Fig. 14) and a decrease in amplitude was prominent above $1200 \mathrm{~Hz}$ when the fruit were stored for 2 weeks.

The phase shift at $400 \mathrm{~Hz}$ was altered somewhat by storage (Fig. 15). However at $800,1,200$, and $1,600 \mathrm{~Hz}$, the phase shift significantly increased during a 2 -week storage period. The second resonance frequency decreased, while the peak height and width fluctuated only slightly during storage (Fig. 16). Upon mechanical texture analysis the maximum imposed force decreased during
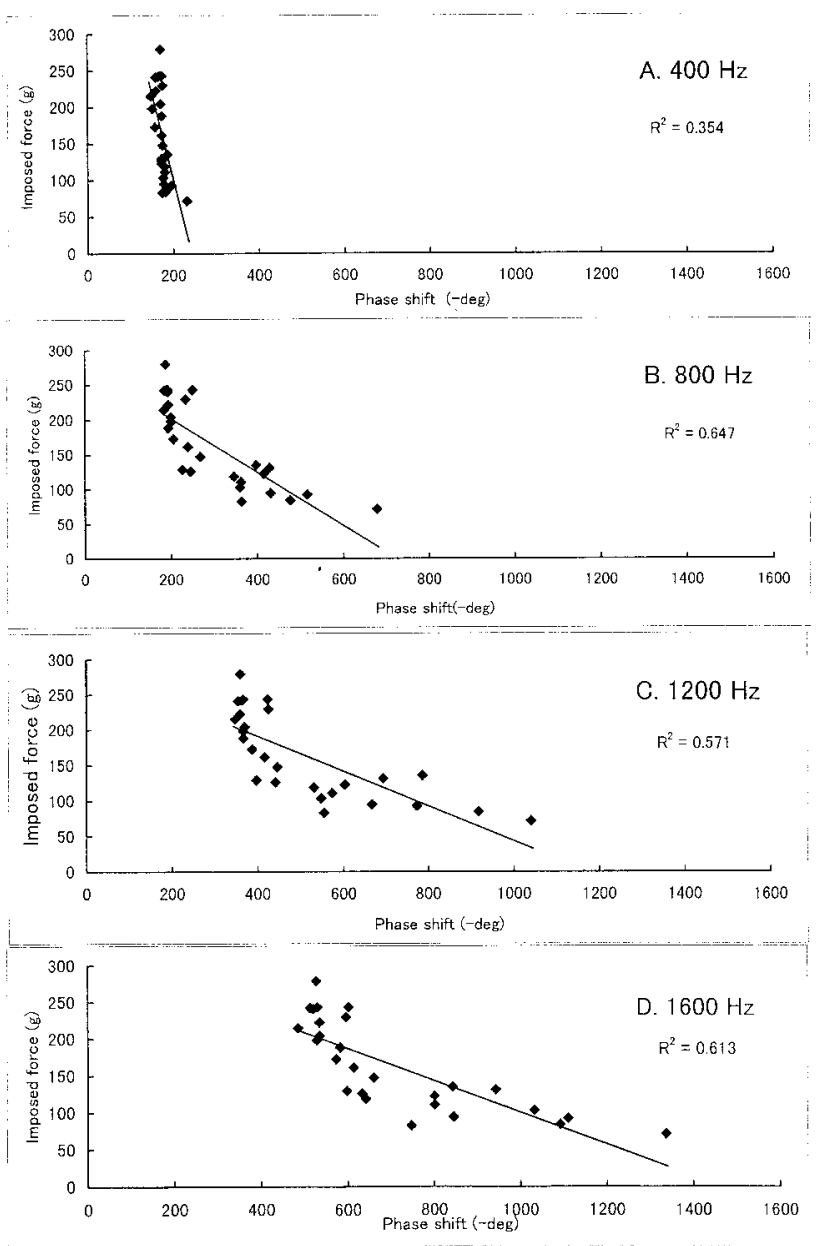

Fig. 13. Relationship between the maximum force imposed by the rheometer and the magnitude of phase shift at (A) $400 \mathrm{~Hz},(\mathbf{B}) 800 \mathrm{~Hz}$, (C) $1200 \mathrm{~Hz}$, and (D) $1600 \mathrm{~Hz}$ in apple. 


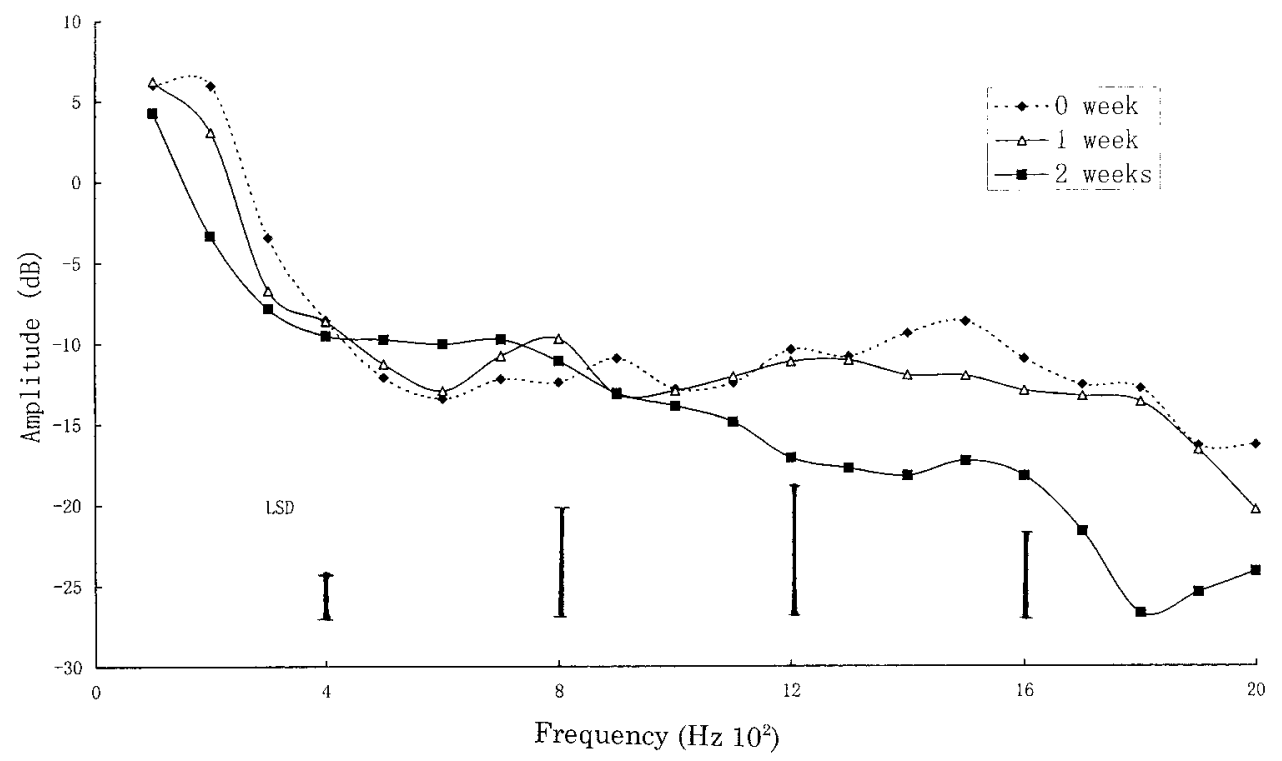

storage, and the result revealed that the outside tissue was firmer than the inner tissue.

\section{Discussion}

In a previous publication (Muramatsu et al., 1999) the output signal of FFT was used as the reference signal of stage vibration. In this report the reference signal was based on the output of accelerometer directly. When the stage vibration was directly monitored by LDV, the signal was essentially identical to the accelerometer signal regardless of imposed frequency. Thus, to acquire the absolute attenuation of vibrational signals transmitted through fruit, the stage vibration must be measured with an accelerometer.

Fig. 14. Changes in frequency in persimmon during storage for 2 weeks. The relationship between imposed frequency and vibration amplitude was taken from the display on the FFT monitor. Vertical bars represent selected LSD $(0.05)$.
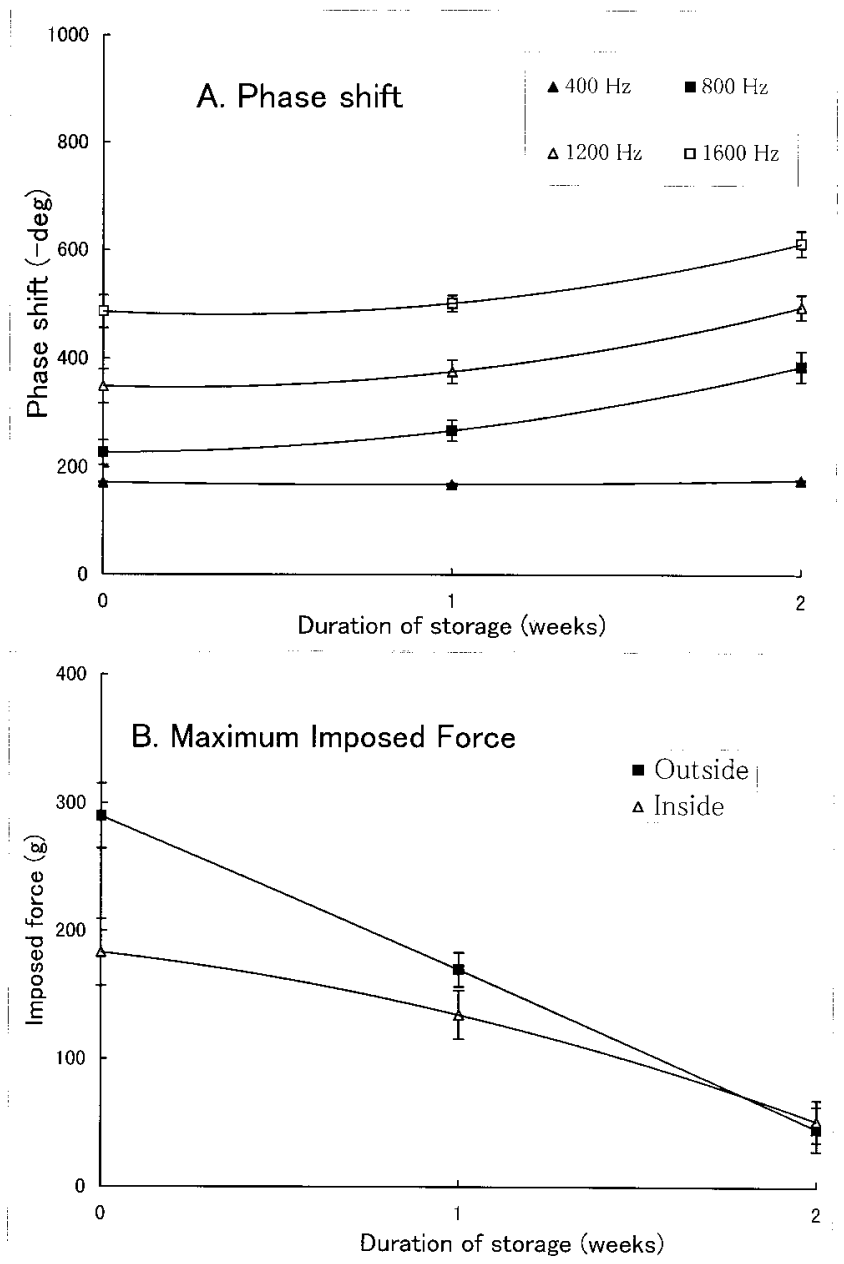

Fig. 15. Changes in parameters related to the firmness during storage of persimmon. (A) The phase shift, (B) the maximum force imposed by a rheometer. See Fig. 3 caption concerning phase shift. Outside and inside indicate the force determined at the location of the $5 \mathrm{~mm}$ from the edge of the fruit and that in the center of the fruit, respectively. Vertical bars indicate SE.
Abbott et al.(1992) found that a second resonance frequency was related to firmness in apple. Our data confirmed that relationship. The second resonance frequency decreased as a function of maturation, and this decrease was associated with a dramatic decrease in the imposed force required to penetrate the tissue as measured by a rheometer (Figs. 5, 10, and 15). The correlation coefficient between second resonance frequency and maximum imposed force was
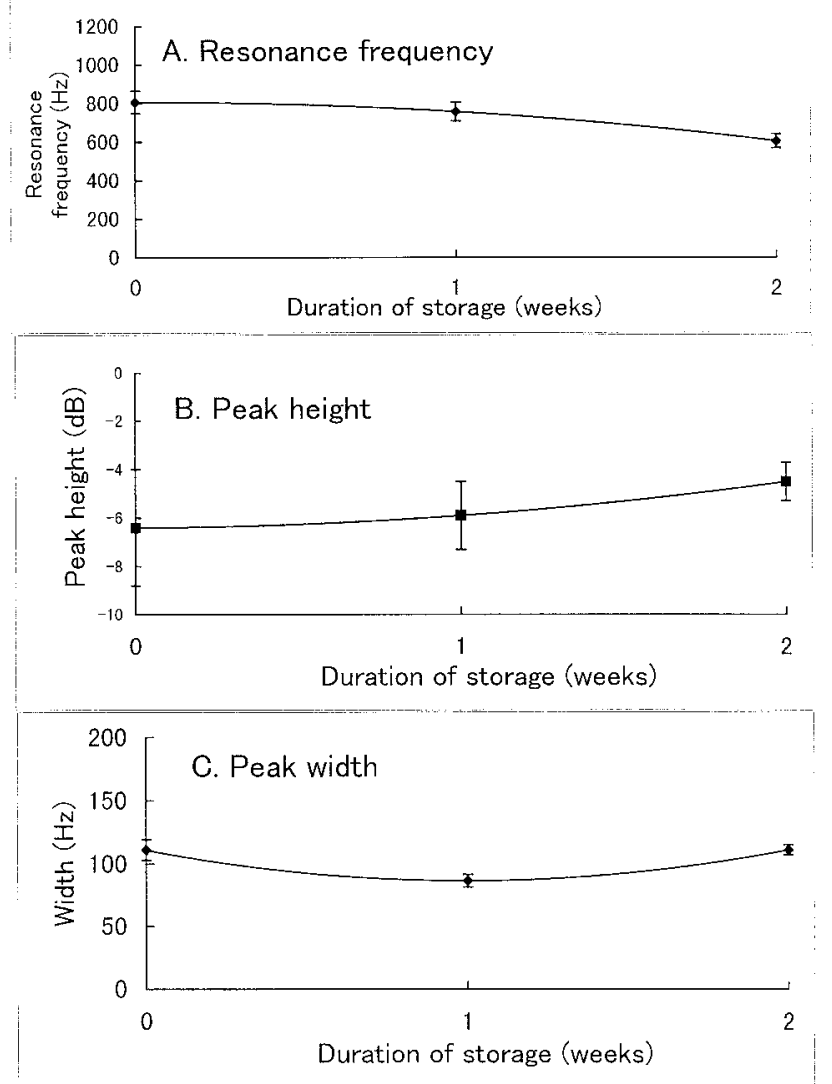

Fig. 16. Changes in parameters related to the second resonance peak during storage of persimmon. (A) Second resonance frequency, (B) peak height, (C) peak width. See Fig. 2 caption for details in determination of the values used in assessing the second resonance. Vertical bars indicate SE. 
significant in kiwifruit and apple (Figs. 7 and 12). Thus, the relationship between the resonance frequency and texture changes does apply to other commodities.

We showed earlier (Muramatsu et al., 1999) that there was a relationship between firmness and phase shift at all the imposed frequencies except $400 \mathrm{~Hz}$ in Japanese pear, peach, and kiwifruit. We now find that a phase shift at 1,200 and 1,600 $\mathrm{Hz}$ increased as a function of maturation in other fruit (Figs. 5, 10, and 15). The correlation coefficient between the magnitude of the phase shift at all given frequencies except $400 \mathrm{~Hz}$ and maximum imposed force measured by the rheometer was significant in kiwifruit and apple (Figs. 8 and 13). These data show that the phase shift was a suitable index for evaluating fruit quality along with the determination of changes in the second resonance frequency.

We found that three resonance frequency parameters were altered by storage: the peak width, peak height, and signal amplitude. While peak height decreased as a function of maturation in apple, we found that this signal was not a reliable maturation index for persimmon and kiwifruit (Figs. 6, 11, and 16). In persimmon and kiwifruit the peak height fluctuated during maturation. The peak width increased in apple with maturation, while in kiwifruit and persimmon the peak width changed little. In excised specimens of watermelon [Citrullus lanatus (Thunb.) Mansf.], the resonance peak yields a simple Gaussian distribution (Yamamoto and Haginuma, 1984b), whereas, in our system, using intact whole fruit, we observed several small peaks clustered in the vicinity of the main peak. Hence the resonance peak was not clearly consistent with a Gaussian distribution. The vibration amplitude did decrease when the imposed frequency was above $1,200 \mathrm{~Hz}$ in all-mature fruit tested (Figs. 4, 9, and 14). While the vibration amplitude might be a useful index for evaluating fruit, internal friction can not be precisely calculated from these parameters since the intact fruit have complex shapes.

Kojima et al. measured the firmness of tomato (1991) and banana (1992) using the intrusive stress relaxation method suggested by Yamamoto et al. (1970). They identified three parameters-minimum stress relaxation time $\left(\mathrm{T}_{0}\right)$, maximum stress relaxation time $\left(\mathrm{T}_{\mathrm{m}}\right)$, and relaxation rate $(\mathrm{r})$ - and found that the $\mathrm{T}_{0}$ value in tomato and both the $\mathrm{T}_{0}$ and the $\mathrm{T}_{\mathrm{m}}$ value in banana decreased during fruit maturation. Sakurai et al. (1979) reported that as $\mathrm{T}_{0}$ decreased there was a corresponding decease in cell wall viscosity resulting from polysaccharide depolymerization. The changes we observed in these studies in the peak height and amplitude are likely to correspond to changes in biochemical structures of cell wall polysaccharides. However, further research is necessary to confirm the direct relationship between wall structure and physical properties of fruit.

In summary, the LDV detection method was shown to be a versatile tool for evaluation of fruit texture. The technique represents an approach that does not require destructive sampling and one that, without contacting the fruit, can quickly acquire pertinent information. While the phase shift with vibrational signal can be used for the evaluation of fruit quality, in addition, the method allows for the acquisition of second resonance frequency responses. We show that the correction of the Doppler laser vibrometer signals picked up signal transduction using accelerometer guarantees the determination of the absolute vibration amplitude of signals altered by transmitted through fruit. The peak height and width of the second resonance frequency and the amplitude of vibration may be suitable indices for evaluating apple quality but appear to be less diagnostic in providing the same information for kiwifruit and persimmon.

\section{Literature Cited}

Abbott, J.A., H.A. Affeldt, and L.A. Lijedahl. 1992. Firmness measurement of stored 'Delicious' apple by sensory methods, Magness-Taylor and sonic transmission. J. Amer. Soc. Hort. Sci. 117:590-595.

Armstrong, P., H.R. Zapp, and G.K. Brown. 1990. Impulsive excitation of acoustic vibrations in apples for firmness determination. Trans. Amer. Soc. Agr. Eng. 33:1353-1359.

Chen, J.Y., M. Miyazato, E. Ishiguro, and N. Nanba. 1993. Detection of firmness in intact pumpkins and Sakurajima radishes by impact forces. J. Jpn. Soc. Hort. Sci. 61:951-956.

Cooke, J.R. and R.H. Rand. 1973. A mathematical study of resonance in intact fruits vegetables using a three media elastic sphere model. J. Agr. Eng. Res. 18:141-157.

Finney Jr., E.E. 1967. Dynamic elastic properties of some fruits during growth and development. J. Agr. Eng. Res. 12:249-256.

Finney, E.E. and K.H. Norris. 1968. Instrumentation for investigating dynamic mechanical properties of fruits and vegetables. Trans Amer. Soc. Agr. Eng. 11:94-97.

Galili, N., A. Mizrach, and G. Rosenhouse. 1993. Ultrasonic testing whole fruit for nondestructive quality evaluation. Trans Amer. Soc. Agr. Eng. 36:6026-6037.

Kojima, K., N. Sakurai, S. Kuraishi, R. Yamamoto, and D.J. Nevins. 1991. Novel technique for measuring tissue firmness within tomato (Lycopersicon esculentum Mill.) fruit. Plant Physiol. 96:545-550.

Kojima K., N. Sakurai, S. Kuraishi, R. Yamamoto, and A. Inaba. 1992. Physical measurement of firmness of banana fruit pulp: Determination of optimum conditions for measurement. Postharvest Biol. Technol. 2:41-49.

Martens, M.J.M. 1990. Laser-doppler vibrometer measurement of leaves, p. 1-22. In: H.F. Linskens and J.F. Jackson (eds.). Physical methods in plant sciences. Springer-Verlag.

Michelsen, A. and O.N. Larsen. 1978. Biophysics of the ensiferan ear. I. Tympanal vibrations in bushcrickets (Tettigoniidae) studied with laser vibrometry. J. Comp. Physiol. 123:193-203.

Mizrach, A., N. Galili, and G. Rosenhouse. 1989. Determination of fruit and vegetable properties by ultrasonic excitation. Trans Amer. Soc. Agr. Eng. 32:2053-2059.

Muramatsu, N., N. Sakurai, N. Wada, R. Yamamoto, T. Takahara, T. Ogata, K. Tanaka, T. Asakura, Y. Ishikawa-Takano, and D.J. Nevins. 1999. Evaluation of fruit tissue texture and internal disorders by laser doppler detection. Postharvest Biol. Technol. 15:83-88.

Muramatsu, N., N. Sakurai, N. Wada, R. Yamamoto, T. Takahara, T. Ogata, K. Tanaka, T. Asakura, Y. Ishikawa-Takano, and D.J. Nevins. 1997. Critical comparison of an accelerometer and a laser Doppler vibrometer for measuring fruit firmness. HortTechnology 7:434-438.

Muramatsu, N, N. Sakurai, R. Yamamoto, and D.J. Nevins. 1996. Nondestructive acoustic measurement of firmness for nectarines, apricots, plums, and tomatoes. HortScience 31:1199-1202.

Rowan, J.D., K.H. Norris, and C.K. Power. 1958. A method for measuring the rheological properties of eggs. Food Res. 23:670-676.

Sakurai, N., K. Nishitani, and Y. Masuda. 1979. Auxin and hydrogen ion induced cell wall loosening and cell extension in Avena coleoptile segment. Plant Cell Physiol. 18:371-380.

Shmulevich, I., N. Galili, and D. Rosenfeld. 1996. Detection of fruit firmness by frequency analysis. Trans Amer. Soc. Agr. Eng. 39:10471055.

Yamamoto, H. and S. Haginuma. 1984a. Estimation of the dynamic Young's modules of apple flesh from the natural frequency of an intact apple. Rpt. Natl. Food Res. Inst. 44:20-25.

Yamamoto, H. and S. Haginuma. 1984b. Dynamic viscoelastic properties and acoustic properties of Watermelons. Rpt. Natl. Food Res. Inst. 44:30-35.

Yamamoto, H. and S. Haginuma. 1984c. Dynamic viscoelastic properties and acoustic properties of Japanese radish (Shogoin) roots. Rpt. Natl. Food. Res. Inst. 44:36-44.

Yamamoto, R., K. Shionozaki, and Y. Masuda. 1970. Stress-relation properties of plant cell walls with special reference to auxin action. Plant Cell Physiol. 11:947-956.

Zebrowski, J. 1992. Complementary patterns of stiffness in stem and leaf sheaths of triticale. Planta 187:301-305. 